\title{
1001 Hygienekonzepte
}

\author{
Maier-Kolumne Hygienekonzepte, Ganzkörperschutz, Formularflut - \\ Außer-Haus-Termine in Pflegeheimen und anderen Institutionen sind für \\ viele Therapeuten derzeit kein Zuckerschlecken. Da braucht es einen langen \\ Atem und viel Geduld - weiß auch Kolumnistin Ulrike Maier.
}

$\rightarrow$ Ich bin die Nummer zwölf in der Schlange, die sich bis zur Straße hinzieht. 1,50 Meter Abstand verlängert inzwischen überall die Anstehstrecke. „Ich will für meine Mutter doch nur neue Wäsche abgeben!“, schreit die Frau hinter mir durch ihren Mundschutz. „Und ich will eigentlich nur meinen Patienten behandeln!“, schreie ich zurück, sonst würde sie mich wegen Abstand und Mundschutz nicht verstehen. Wir sehen beide den Eingang noch nicht.

Während ich unter der FFP2-silberdurchwirkten Deluxe-MNS-Variante zu schwitzen

\section{D5}

\section{Getauschte Rollen: Wartezeit für Therapeuten}

beginne, brummt das Handy. Es ist die Kollegin. „Ich habe gerade Nachrichten von der Institution für betreutes Wohnen bekommen. Du kannst dort ab sofort wieder die Leute behandeln. Sie haben auf dem Rasen einen Pavillon aufgestellt. Du müsstest eine mobile Liege mitbringen, Flächendesinfektion und ein Ganzkörperschutz stehen bereit, zum Abschluss soll der Boden noch mit 99-ProzentKeimtötungsreiniger gewischt werden.“ „Ein Ganzkörperanzug für sechs Patienten? Da kann ich es auch gleich sein lassen, oder? Und danach noch putzen? Fünf Jahre Ausbildung, und jetzt das!“, stöhne ich. „Von allen Hygienekonzept-Varianten finde ich den Pavillon aber am romantischsten.“ „Wie Urlaub....", sinniere ich. „Als es noch Urlaub gab...., sagt die Kolle- gin, und beide seufzen wir gleichzeitig „systemrelevant“. „Wo bist du?“, fragt sie dann. „Ich stehe hier im Seniorenheim für einen Patienten mindestens eine halbe Stunde an“, sage ich. „Die messen Fieber, ich muss jedes Mal drei Seiten Formulare ausfüllen und danach warte ich auf eine Schwester, die mich zum Zimmer begleitet.“ „Mein Heim hat immer noch total geschlossen. Wenigstens darfst du rein!“ „Ja“, lache ich. „Porentief rein ... also Geld verdienen sieht anders aus! Wenigstens ist der Patient nett und unendlich dankbar!“

Nach dem Ende des Telefonats bin ich schon drei Meter weiter und sehe immerhin den Eingang. Eine E-Mail wird auf meinem Smartphone angezeigt. Die Antwort auf meine Anfrage bei der Seniorenresidenz. Ich will dort postoperativ einen Patienten behandeln, den ich schon seit fünf Jahren kenne.

Liebe Frau Maier, wir brauchen von Ihnen ein Hygienekonzept, bevor wir Sie zum Patienten lassen dürfen, und einen Hinweis auf die Relevanz Ihrer Behandlung. Grüße, Herr Schmidt.

Ich bin irritiert, außerhalb der Praxis haben die Heime ein eigenes Hygienekonzept. Und jede Institution eine andere Lösung, meist aber alkoholischer Art mit der Prozentzahl 99,9 drauf. Egal, ich steh ja rum, kann ich auch ein Hygienekonzept schicken.

Lieber Herr Schmidt, wir behandeln mit FFP2Masken, waschen vorher und nachher 30 Sekunden unsere Hände (schon immer) und desinfizieren sie. Da es sich nur um einen Patienten handelt, kann ich einen Ganzkörperschutz und Einmalhandschuhe selber mitbringen, obwohl diese momentan Mangelware sind. Auch eine
Handdesinfektion habe ich immer bei mir. Ich nehme ab Betreten Ihres Hauses den direktesten Weg zum Zimmer meines Patienten. Auch halte ich mich nicht länger, als die Behandlungszeit dauert, im Haus auf. Seit dem Aussetzen der Physiotherapie hat sich der Zustand des Patienten laut Aussage seiner Frau stark verschlechtert. Deswegen ist eine Behandlung dringend notwendig.

1,50 Meter weiter kommt die Antwort.

@ Nach Absprache mit der Residenzleitung habe ich folgende Info für Sie: Sie müssen ein richtiges Konzept schicken, nicht so eine E-Mail. Dort müssen Sie akribisch ausführen, was sie tun, sobald sie das Haus betreten. Sie müssen die Hygienemaßnahmen aufführen, die Sie während des ganzen Besuches machen, vor, während, nach der Anwendung und in der Nachbereitung. An der Rezeption müssen Sie außerdem noch zusätzlich ein Formular ausfüllen.

\section{פy \\ Hygienekonzepte zerren an den Nerven.}

Hinter mir setzt sich die Frau auf den Boden. „Das macht mich grad alles sehr müde!“, sagt sie, als hätte sie meine E-Mail gelesen. Noch drei Leute vor dem Eingang. Ich tippe.

Lieber Herr Schmidt, die Zeiten sind für uns alle schwer, aber: Das ist jetzt nicht Ihr Ernst, oder? Sie dokumentieren, wann ich komme und zu wem, ich dusche mich in Desinfektion und hülle mich in Schutzkleidung aller Art, was genau 


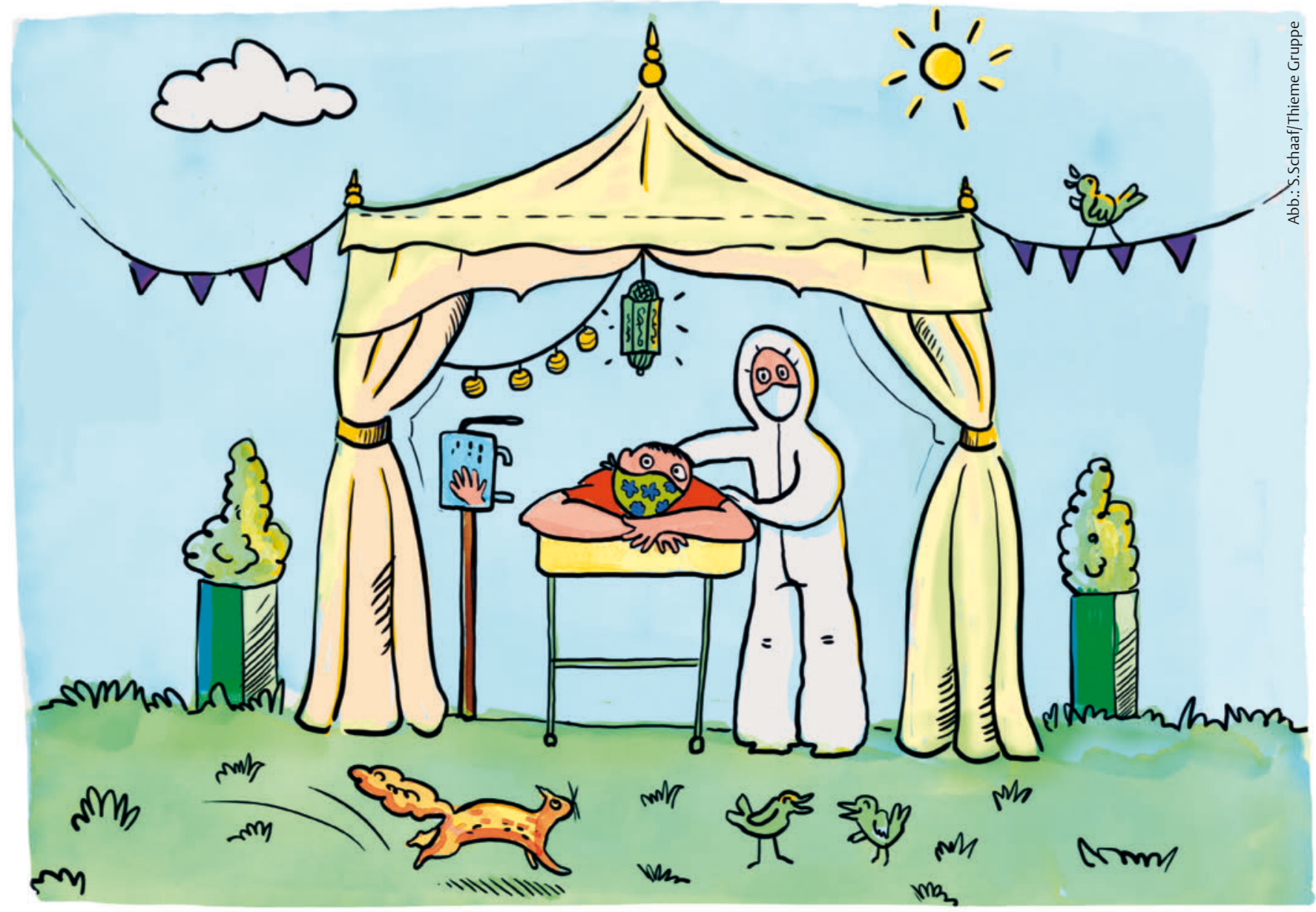

brauchen Sie denn noch für ein Konzept? Den Therapiebericht?

Nur noch zwei Leute vor mir.

Das Land Hessen macht Auflagen, beschweren Sie sich dort. Schicken Sie eine PDF-Datei, und das Dokument muss als Hygienekonzept erstellt und deklariert sein. Sie können untergliedern in Unterpunkte wie Abstandskonzept, wann und wo Sie die Hände waschen usw. Eine korrekte Bürokratie ist wichtig. Ich komme Ihnen so gut es geht entgegen!

„Ich werde gleich sauer“, sagt die Frau hinter mir, weil grad wieder gar nichts vorwärtsgeht. @ Bloß nicht entgegenkommen, schreibe ich zurück, @ halten Sie sich bitte an die Abstandsund Anstandsregeln. Gerade wird mir Fieber gemessen, und trotz meines wütend hoch- schnellenden Blutdrucks habe ich keine Temperatur. Dann darf ich ins Haus, aber nur wenn ich das Handy ausstelle. Eine Serviceangestellte gibt mir einen Zettel in die Hand. Darauf steht: Hygienekonzept. In Stichworten, aber ausführlich.

\section{5}

\section{Die Zeit der kreativen Lösungen ist gekommen.}

Als ich das Haus verlasse, schneide ich den Briefkopf ab, unterschreibe, stecke das Papier sofort in einen Umschlag und sende ihn zu Händen Herrn Schmidt. Zwei Tage später stehe ich im Pavillon bei meiner Patientin, die Sonne wärmt mir den Rücken, es riecht nach frisch gemähtem Gras, und eine Nachricht wird auf dem Smartphone angezeigt. @ Können kommen. Keine Grüße, kein Name, man spürt auch so, wer hier angefressen ist.

Ich mache ein Bild von meiner Arbeitsstätte, und weil ich grad Zeit und Lust habe, erstelle ich meine aktuelle Arbeitsplatzbeschreibung. Dann schicke ich alles per E-Mail an Herrn Schmidt mit den Worten: @ , 99,9 Prozent aller Therapeuten bewerteten dieses Tiny House mit fünf Sternen bezüglich Gastfreundlichkeit, Hygiene und Sauberkeit. “

Ich darf die Residenz mittlerweile ungehindert betreten, die Leitungsebene verkehrt nur noch schriftlich mit mir. „Immerhin antiviral“, denke ich mir schmunzelnd. Mal sehen, was der Winter an kreativen Lösungen für uns bringen mag.

Ulrike Maier 